\title{
Initiation of breastfeeding within one hour of birth among mothers with infants younger than or equal to 6 months of age attending public health institutions in Addis Ababa, Ethiopia
}

\author{
Meseret Ekubay ${ }^{1}$, Aster Berhe $^{2}$ and Engida Yisma ${ }^{3,4^{*}}$
}

\begin{abstract}
Background: Breast milk is comprised of the essential nutrients that an infant needs in the first six months of life. Timely initiation of breastfeeding guarantees that infants receive the colostrum, 'the first breastmilk', which contains antibodies that protect the newborn against diseases. Breastfeeding within the first hour of life prevents newborn death due to sepsis, pneumonia, diarrhea and hypothermia. Although breastfeeding is a common practice in subSaharan Africa, evidence show that early initiation of breastfeeding is low.

Methods: We conducted a cross-sectional study of 583 mothers with infants younger than or equal to 6 months of age attending Maternal and Child Health $(\mathrm{MCH})$ clinics of public health institutions in Addis Ababa, Ethiopia from April to May 2012. A simple random sampling design was used to select the institutions included in this study. Data from mothers of infants were collected using interviewer-administered questionnaire. We analyzed the data to examine factors associated with initiation of breastfeeding within one hour of birth using logistic regression models.

Results: Of 564 (96.7\%, 564/583) mothers who breastfed their infants, 58.3\% (329/564) initiated breastfeeding within one hour of birth. In the adjusted analysis, mothers who had three or more infants had about twice higher odds of timely initiation of breastfeeding within one hour of birth (Adjusted Odds Ratio [aOR] 2.10; 95\% Confidence Interval $[\mathrm{CI}] 1.04,4.30)$ compared with mothers who had one infant. Furthermore, women who started antenatal care at their fourth month of pregnancy or later had a $49.0 \%$ higher odds of initiation of breastfeeding within one hour of birth (aOR 1.49; 95\% Cl 1.01, 2.19) compared to mothers who started antenatal care before their fourth month of pregnancy.

Conclusions: Initiation of breastfeeding within one hour of birth was low. Initiation of breastfeeding within one hour of birth was highest among multiparous women, mothers aged 30-34 years, and women who began antenatal care at their fourth month of pregnancy or later. Public health officials and health care providers should consider interventions to promote and support early initiation of breastfeeding.
\end{abstract}

Keywords: Initiation of breastfeeding, Public health institution, Addis Ababa, Ethiopia

* Correspondence: engiday@gmail.com

${ }^{3}$ School of Allied Health Sciences, College of Health Sciences, Addis Ababa

University, Addis Ababa, Ethiopia

${ }^{4}$ Robinson Research Institute, School of Medicine, The University of Adelaide,

Adelaide, Australia

Full list of author information is available at the end of the article 


\section{Background}

More than four million neonatal deaths occur every year, and most of these deaths are from low- and middleincome countries [1]. Breastfeeding within the first hour of life provides protection against infection and has been shown to prevent neonatal death due to sepsis, pneumonia, diarrhea and hypothermia [2-4]. Conversely, it was found that delayed initiation of breastfeeding after the first hour of birth doubled the risk of neonatal mortality [5].

The World Health Organization (WHO) recommends initiation of breastfeeding within one hour of birth [6]. However, the proportion of early initiation of breastfeeding among mothers varies widely across countries and regions worldwide. Factors that are often associated with timely initiation of breastfeeding include mother's education [7-9], place of residence [10, 11], household income $[12,13]$, Place of birth [14], mother's occupation [12, 15], cultural beliefs and/or traditional feeding practices $[4,16-$ $18]$, counselling services provided during antenatal and postnatal visits $[10,13]$, and parity $[9,12]$, although these factors may differ according regions and states.

Previous studies revealed that cultural beliefs and traditional feeding practices may prevent mothers initiating breastfeeding immediately postbirth in developing settings. For example, in one systematic review involving 25 observational studies, it was found that women initiated breastfeeding in the evening after seeing stars if the child was born in morning due to cultural beliefs, and women discarded colostrum because of the negative perception that it may harm the newborn [4]. Furthermore, Legesse and colleagues in their cross-sectional study conducted in North-eastern Ethiopia demonstrated that late initiation of breastfeeding was associated with prelacteal feeding practice such as raw butter feeding [18], which is typically administered via a finger and perceived to be good for the health of newborns instead of colostrum.

In Addis Ababa, Ethiopia about $62.3 \%$ of births were born in public health institutions [19]. In 2004, the Family Health Department of Federal Ministry of Health of Ethiopia developed a national strategy for infant and young child feeding which states breastfeeding should begin within one hour after birth [20]. However, in Addis Ababa, there is limited insight regarding the prevalence and factors associated with timely initiation of breastfeeding among urban mothers. The purpose of this study was to estimate the prevalence and examine factors associated with initiation of breastfeeding within one hour of birth among urban mothers with infants younger than or equal to 6 months of age attending public health institutions in Addis Ababa, Ethiopia.

\section{Methods}

\section{Study setting}

This study was conducted in Addis Ababa, the capital city of Ethiopia and seat of African Union and United
Nations World Economic Commission for Africa. The study participants were recruited at Maternal and Child Health $(\mathrm{MCH})$ clinics of public health institutions in Addis Ababa.

\section{Study design}

We used a cross-sectional study design and intervieweradministered questionnaires to collect data from mothers of infants younger than or equal to 6 months of age attending $\mathrm{MCH}$ clinics of public health institutions in Addis Ababa. Mothers who gave birth within the six months prior to the study were included in order to reduce the bias that may occur due to data collection with a longer recall period.

\section{Sample size and sampling}

Sample size was estimated using a single population proportion formula and calculated with the following assumptions: $95 \%$ confidence level, 5\% margin of error, and $62 \%$ expected prevalence of initiation of breastfeeding within one hour of birth among mothers in public health institutions in Addis Ababa, Ethiopia (based on a Demographic and Health Survey [DHS] finding reported in Ethiopia) [20]. Given these assumptions, the required sample size was found to be 362 . Considering a conservative design effect of 1.5 for complex sampling, and a non-response rate of $10 \%$, the final estimate was 597 . Thus, a total of 597 mothers of infants attending $\mathrm{MCH}$ clinic of public health institutions in Addis Ababa were identified.

The total number of public health institutions in Addis Ababa was 49 (13 hospitals and 38 health centers). Of these, 10 health centers and 2 hospitals (i.e., a total of 12 public health institutions) were selected by simple random sampling design. The sample was then allocated to the institutions included in the current study proportional to the number of mothers attending $\mathrm{MCH}$ clinics of the respective health institutions. Average daily records of the number of clients available at $\mathrm{MCH}$ clinics were used in each institution for this purpose. And, at each study center, all mothers with infants younger than or equal to six months of age and presented to the $\mathrm{MCH}$ clinics of public health institutions from April to May 2012 were interviewed.

\section{Data collection}

The questionnaire for this study was adapted from the Ethiopian 2011 DHS [20] and through review of relevant studies. The questionnaire was initially prepared in English and translated into Amharic. Before the actual data collection, the questionnaire was pretested for comprehension among mothers of infants younger than or equal to six months of age recruited from a nearby public health institution outside of the study area, and 
revisions were incorporated into the questionnaire. The data were collected by 10 health professionals (nurses and midwives) after two days training about the tool and techniques of data collection. Data collection sessions were arranged by communicating with concerned bodies in Addis Ababa health bureau and the selected public health institutions.

\section{Study variables}

The outcome of interest was the proportion of mothers of infants who initiated breastfeeding within one hour of birth. Initiation of breastfeeding within one hour of birth was computed based on one question that enquires about the time at which mother's recent infant was put to the breast immediately after birth for the first time. We examined how mother's age, religion, ethnicity, marital status, media exposure, having home visit by health extension worker, parity, mother's education, mother's occupation, number of months pregnant at time of first antenatal care visit, mother's attendance of health education/counselling, place of delivery, and household income affected the variability in initiation of breastfeeding within the first hour of birth.

In Ethiopia, health extension workers are salaried female community health workers with secondary-level school education who have completed a one-year training in basic health service delivery. They are selected from the community that they serve, to ensure local familiarity, and work at 75\% time [21]. Mother's attendance of health education/counselling was measured using 7 questions that entail whether or not health workers informed/counselled mothers regarding placing baby in skin-to-skin contact with the mother immediately after birth; timely initiation of breastfeeding; hand washing before taking care of baby; immunization; danger signs of the newborn; cord care; and care for low birth weight baby. Responses to these questions were dichotomized into satisfactory (when mothers answered correctly four or more questions) and unsatisfactory (less than four questions answered correctly). In order to rank monthly income status of study participants, we utilized the cutoff described by Mengesha et al. [22] as low (<500 ETB (Ethiopian birr)), medium (500-2000 ETB), and rich (>2000 ETB).

\section{Statistical analysis}

The data were entered using Epi Info version 3.5.1 (CDC, Atlanta, GA, USA), and then exported to SPSS version 23.0 (IBM, Armonk, NY, USA) for further processing. All required variable recoding and transformation were done before the final data analysis. Frequency distributions, and cross-tabulations were used to describe the variables of the study. To examine factors associated with initiation of breastfeeding within one hour of birth, we calculated unadjusted and adjusted odds ratios (aOR) and their $95 \%$ CIs using logistic regression models. We identified variables that were associated with initiation of breastfeeding based on unadjusted analyses as well as through literature review. The variable incorporated in the final model based on unadjusted analyses include parity, number of months pregnant at time of first antenatal care visit, and mother's attendance of health education/counselling. Mother's age, mother's education, and mother's occupation were the other variables that were included based on the literature.

\section{Results}

Of 597 mother-infant dyads approached, 583 mothers participated in the study (response rate 97.7\%). The average age of participants was 25.7 years $( \pm$ standard deviation $=4.4$ years). By ethnicity, the majority $(47.86 \%)$ of the participants are Amhara and the majority of mothers $(89.71 \%)$ were married. Initiation of breastfeeding within one of birth was highest among mothers in the age category of 30-34 years, mothers with secondary or more education, mothers who had two or more children, and women who started their first antenatal care visit at their fourth months of pregnancy or later. Compared with mothers who initiated breastfeeding after one hour of birth, more mothers who initiated breastfeeding within the first hour of birth gave birth at public hospitals and health centers. Details regarding characteristics of the study participants according to initiation of breastfeeding are given in Table 1 .

\section{Breastfeeding practices}

Of 583 participants, 564 (96.7\%, 564/583) practiced breastfeeding. Of these 564 mothers, 58.3\% (329/564) initiated breastfeeding within the first hour of birth. Of all breastfed mothers, $33.0 \%$ of them practiced mixed feeding.

\section{Factors associated with initiation of breastfeeding within one hour of birth}

Compared to mothers in the age category of 15-19 years, mothers aged 20-24 years had about three times higher odds of initiation of breastfeeding within one hour of birth (adjusted odds ratio (aOR 2.85; 95\%CI 1.09, 7.47). Mothers who had three or more infants had about twice higher odds of initiation of breastfeeding within one hour of birth (aOR 2.10; 95\% CI 1.04, 4.30) compared to mothers who had one infant.

Mothers who started antenatal care at their fourth month of pregnancy or later had a $49.0 \%$ higher odds of initiating breastfeeding within one hour of birth (aOR 1.49; $95 \%$ CI 1.01, 2.19) relative to mothers who started antenatal care before their fourth month of pregnancy. Likewise, initiation of breastfeeding within one hour of 
Table 1 Characteristics of the study participants according to initiation of breastfeeding among mothers of infants attending public health institutions

\begin{tabular}{|c|c|c|c|}
\hline \multirow[t]{2}{*}{ Characteristics } & \multirow{2}{*}{$\begin{array}{l}\text { Overall } \\
(n=583)\end{array}$} & \multicolumn{2}{|c|}{ Initiation of breastfeeding $^{a}$} \\
\hline & & $\begin{array}{l}\text { Within } 1 \mathrm{~h} \\
(n=329)\end{array}$ & $\begin{array}{l}\text { After } 1 \mathrm{~h} \\
(n=235)\end{array}$ \\
\hline \multicolumn{4}{|l|}{ Mother's age } \\
\hline $15-19$ & $33(5.66)$ & 17/32 (53.13) & $15 / 32(46.88)$ \\
\hline $20-24$ & $202(34.65)$ & 117/196 (59.69) & 79/196 (40.31) \\
\hline $25-29$ & $222(38.08)$ & $117 / 217(53.92)$ & $100 / 217(46.08)$ \\
\hline $30-34$ & $116(19.90)$ & $72 / 110(65.45)$ & $38 / 110(34.55)$ \\
\hline $35+$ & $10(1.72)$ & $6 / 9(66.67)$ & 3/9 (33.33) \\
\hline \multicolumn{4}{|l|}{ Religion } \\
\hline Orthodox & $398(68.27)$ & $232 / 383(60.57)$ & 151/383 (39.43) \\
\hline Muslim & $102(17.50)$ & $56 / 100(56.00)$ & $44 / 100(44.00)$ \\
\hline Protestant & $80(13.72)$ & 40/78 (51.28) & $38 / 78(48.72)$ \\
\hline Catholic & $3(0.51)$ & $1 / 3(33.33)$ & $2 / 3(66.67)$ \\
\hline \multicolumn{4}{|l|}{ Ethnicity } \\
\hline Amhara & $279(47.86)$ & $168 / 269(62.45)$ & $101 / 269(37.55)$ \\
\hline Oromo & $110(18.87)$ & $60 / 108(55.56)$ & 48/108 (44.44) \\
\hline Tigre & $49(8.40)$ & 25/47 (53.19) & $22 / 47(46.81)$ \\
\hline Gurage & $95(16.30)$ & $50 / 92(54.35)$ & $42 / 92(45.65)$ \\
\hline Others $^{b}$ & $50(8.58)$ & $26 / 48(54.17)$ & $22 / 48(45.83)$ \\
\hline \multicolumn{4}{|l|}{ Marital status } \\
\hline Not married & $32(5.49)$ & $19 / 29(65.52)$ & $10 / 29(34.48)$ \\
\hline Married & $523(89.71)$ & 295/508 (58.07) & $213 / 508(41.93)$ \\
\hline Divorced & $26(4.46)$ & $14 / 25(56.00)$ & $11 / 25(44.00)$ \\
\hline Widowed & $2(0.34)$ & $1 / 2(50.00)$ & $1 / 2(50.00)$ \\
\hline \multicolumn{4}{|l|}{ Mother's education } \\
\hline No education & $67(11.49)$ & $38 / 66$ (57.58) & 28/66 (42.42) \\
\hline Primary & $143(24.53)$ & 73/139 (52.52) & 66/139 (47.48) \\
\hline Secondary or more & $373(63.98)$ & 218/359 (60.72) & $141 / 359(39.28)$ \\
\hline \multicolumn{4}{|l|}{ Mother's occupation } \\
\hline Employed & $222(38.08)$ & $124 / 213(58.22)$ & 89/213 (41.78) \\
\hline Not employed & 361 (61.92) & 205/351 (58.40) & $146 / 351(41.60)$ \\
\hline \multicolumn{4}{|l|}{ Household income } \\
\hline Low & $63(10.81)$ & $38 / 60(66.33)$ & $22 / 60(36.67)$ \\
\hline Middle & $437(74.96)$ & $241 / 426(56.57)$ & $185 / 426(43.43)$ \\
\hline High & $83(14.24)$ & $50 / 78(64.10)$ & 28/78 (35.90) \\
\hline \multicolumn{4}{|l|}{ Media exposure } \\
\hline Yes & 449 (77.02) & 250/433 (57.74) & $183 / 433(42.26)$ \\
\hline No & $134(22.98)$ & 79/131 (60.31) & $52 / 131$ (39.69) \\
\hline
\end{tabular}

Had home visit by health extension worker

$\begin{array}{cccc}\text { Yes } & 132(22.64) & 245 / 437(56.06) & 192 / 437(43.94) \\ \text { No } & 451(77.36) & 84 / 127(66.14) & 43 / 127(33.86) \\ \text { Parity } & & & \\ 1 & 371(63.64) & 199 / 359(55.43) & 160 / 359(44.57)\end{array}$

Table 1 Characteristics of the study participants according to initiation of breastfeeding among mothers of infants attending public health institutions (Continued)

\begin{tabular}{|c|c|c|c|}
\hline \multirow[t]{2}{*}{ Characteristics } & \multirow{2}{*}{$\begin{array}{l}\text { Overall } \\
(n=583)\end{array}$} & \multicolumn{2}{|c|}{ Initiation of breastfeeding ${ }^{a}$} \\
\hline & & $\begin{array}{l}\text { Within } 1 \mathrm{~h} \\
(n=329)\end{array}$ & $\begin{array}{l}\text { After } 1 \mathrm{~h} \\
(n=235)\end{array}$ \\
\hline 2 & $141(24.19)$ & $83 / 138(60.14)$ & $55 / 138(39.86)$ \\
\hline $3+$ & $71(12.18)$ & $47 / 67(70.15)$ & 20/67 (29.85) \\
\hline \multicolumn{4}{|c|}{ Number of months pregnant at time of first antenatal care visit $(n=565)$} \\
\hline$<4$ & $224(39.65)$ & $113 / 214(52.80)$ & $101 / 214(47.20)$ \\
\hline $4+$ & $341(60.35)$ & 204/332 (61.45) & 128/332 (38.55) \\
\hline \multicolumn{4}{|l|}{ Place of delivery } \\
\hline Home & $21(3.60)$ & $10 / 19(52.63)$ & $9 / 19(47.37)$ \\
\hline Public hospital & $232(39.89)$ & $124 / 228(54.39)$ & $104 / 228(45.61)$ \\
\hline Private hospital & $58(9.95)$ & $27 / 24(50.00)$ & $27 / 24(50.00)$ \\
\hline Health center & 269 (46.24) & $166 / 261(63.60)$ & $95 / 261(36.40)$ \\
\hline Others $^{\complement}$ & $3(0.51)$ & $2 / 2(100.00)$ & $0(0.00)$ \\
\hline
\end{tabular}

${ }^{\mathrm{a}}(n=19)$ mothers of infants did not practice breastfeeding

Include; Wolyita, Kanbata, Silete, Gamebella and Somali ethnicities

${ }^{\mathrm{c}}$ Non-governmental organization and private clinics

birth was associated with mother's attendance of health education/counselling (aOR 2.27; 95\% CI 1.54, 3.36). Table 2 summarizes the results on factors associated with initiation of breastfeeding within one hour of birth.

\section{Discussion}

This study assessed the prevalence and factors associated with initiation of breastfeeding within one hour of birth among mothers of infants younger than or equal to 6 months age. We found that $58.3 \%$ of mothers of infants initiated breastfeeding within one hour of birth, suggesting poor practice of timely initiation of breastfeeding among mothers. This figure was, however, somewhat higher than the findings reported in previous studies completed in Arba Minch (57.0\%) [23] and Goba (52.0\%) [10] towns in Ethiopia. Nonetheless, the finding of the present study is far from the WHO recommendation that states all mothers should initiate breastfeeding within the first hour of birth [6]. As our study focused on urban mothers living in Addis Ababa (the capital of Ethiopia), the prevalence should have been much higher than the prevalence that reported in other parts of Ethiopia. It is quite clear that urban mothers have increased access to health care and health literacy compared with those who live in small towns or rural areas. Thus, interventions such as health education to urban mothers are required to promote initiation of breastfeeding within one hour of birth.

The finding of this study showed that mothers who had three or more infants have about twice higher odds of initiation of breastfeeding within one hour of birth relative to mothers who had one infant. This is 
Table 2 Logistic regression analysis showing the odds ratio for initiation of breastfeeding within one hour of birth among mothers in relation to mother's characteristics

\begin{tabular}{|c|c|c|c|}
\hline Predictor & $\begin{array}{l}\% \text { initiation of breastfeeding } \\
\text { within } 1 \mathrm{~h}(n=564)\end{array}$ & $\begin{array}{l}\text { Unadjusted OR } \\
(95 \% \mathrm{Cl})\end{array}$ & $\begin{array}{l}\text { Adjusted OR }{ }^{a} \\
(95 \% \mathrm{Cl})\end{array}$ \\
\hline \multicolumn{4}{|l|}{ Mother's age } \\
\hline $15-19$ & 3.0 & 1 & 1 \\
\hline $20-24$ & 20.7 & $1.31(0.61,2.77)$ & $2.85(1.09,7.47)$ \\
\hline $25-29$ & 20.7 & $1.03(0.49,2.17)$ & $1.93(0.72,5.13)$ \\
\hline $30-34$ & 12.8 & $1.67(0.75,3.70)$ & $2.50(0.87,7.17)$ \\
\hline $35+$ & 1.1 & $1.76(0.37,8.31)$ & $1.79(0.30,10.43)$ \\
\hline \multicolumn{4}{|l|}{ Mother's education } \\
\hline No education & 6.7 & 1 & 1 \\
\hline Primary & 12.9 & $0.78(0.43,1.43)$ & $0.90(0.46,1.78)$ \\
\hline Secondary or more & 38.7 & $1.09(0.64,1.88)$ & $1.36(0.72,2.55)$ \\
\hline \multicolumn{4}{|l|}{ Mother's occupation } \\
\hline Employed & 22.0 & 1 & 1 \\
\hline Not employed & 36.3 & $1.00(0.74,1.42)$ & $1.04(0.70,1.54)$ \\
\hline \multicolumn{4}{|l|}{ Parity } \\
\hline 1 & 35.3 & 1 & 1 \\
\hline 2 & 14.7 & $1.21(0.81,1.81)$ & $1.04(0.66,1.64)$ \\
\hline $3+$ & 8.3 & $1.89(1.08,3.32)$ & $2.1(1.04,4.30)$ \\
\hline \multicolumn{4}{|c|}{ Number of months pregnant at time of first antenatal care visit } \\
\hline$<4$ & 20.0 & 1 & 1 \\
\hline $4+$ & 36.2 & $1.42(1.01,2.01)$ & $1.49(1.01,2.19)$ \\
\hline \multicolumn{4}{|c|}{ Mother's attendance of health education/ counselling ${ }^{b}$} \\
\hline Unsatisfactory & 14.4 & 1 & 1 \\
\hline Satisfactory & 40.2 & $2.21(1.52,3.20)$ & $2.27(1.54,3.36)$ \\
\hline
\end{tabular}

${ }^{a}$ Mutually adjusted; $n=$ total number of mothers who experience breastfeeding

${ }^{\mathrm{b}} \mathrm{S}$ ee the methods section for description of how this variable was computed

consistent with previous studies conducted in Nigeria [12] and Saudi Arabia [24], indicating that multiparty is associated with timely initiation of breastfeeding. Similarly, a study completed in Amibara district, Northeastern Ethiopia showed that mothers who have 2-3 children were less likely to initiate timely breastfeeding compared to those who had four or more children [9]. These findings may suggest that if a mother had more childbirth experience, the next infant is more likely to be put to the breast within one hour life.

Mothers who started antenatal care at their fourth month of pregnancy or later had a $49.0 \%$ higher odds of initiating breastfeeding within one hour of birth relative to mothers who started antenatal care before their fourth month of pregnancy. This may imply that health education/advice provided during antenatal visits at later months of pregnancy appear to be important. Likewise, the present study revealed that initiation of breastfeeding within one hour of birth was associated with mother's attendance of health education/counselling, which is consistent with a study conducted in Goba town in Ethiopia [10], demonstrating that postnatal care advice/counseling about breastfeeding was associated with early initiation of breastfeeding. These findings suggest that health education/ counseling is an important intervention for promoting early initiation of breastfeeding.

The study has notable limitations. First, the study was conducted five years ago and the prevalence of initiation of breastfeeding with one hour of birth reported in the current study might have changed in recent years. However, we believe that the findings are still relevant as the study was designed to include only urban mothers of infants presented to public health facilities, and examined factors associated with initiation of breastfeeding within one hour of birth. Besides, unlike few previous studies conducted in different parts of Ethiopia, the current study included urban mothers with infants younger than or equal to six months age, leaving little room for the possibility of recall/information bias. Secondly, as this study is confined to mothers of infants who attended public health facilities in Addis Ababa, the findings may not be generalizable to mothers who presented to 
private health facilities as well as to those who did not visit any other health institutions in Addis Ababa. Thirdly, as we did not collect information regarding expressed breast milk feeding, babies may be fed expressed breast milk and reported that they were breastfed by mothers, which technically may not be breastfeeding. Finally, this study did not collect data on history of method of birth, and as caesarean section may be associated with lack of early initiation of breastfeeding [4], this would have relevant to collect.

\section{Conclusions}

Initiation of breastfeeding within one hour of birth was low among mothers with infants younger than or equal to 6 months of age attending public health institutions in Addis Ababa. However, as the data for this study was collected several years ago, the current prevalence of timely initiation of breastfeeding might have changed. Early initiation of breastfeeding was highest among mothers aged 30-34 years and multiparous mothers. Public health officials and health care providers should consider interventions to promote and support timely initiation of breastfeeding.

\section{Abbreviations}

DHS: Demographic Health Survey; ETB: Ethiopian Birr; MCH: Maternal and Child Health; WHO: World Health Organization

\section{Acknowledgements}

The authors would like to acknowledge the study participants for their time and engagement in this study. The data collectors - Nurses and Midwivesmade data collection possible and the authors are grateful.

\section{Funding}

This study was funded by Addis Ababa University, Addis Ababa, Ethiopia. The University had no role in the design of the study and collection, analysis, and interpretation of data and in writing the manuscript.

\section{Availability of data and materials}

The dataset used during the current study are available from the corresponding author on reasonable request.

\section{Authors' contributions}

All authors (ME, $A B$ and $E Y$ ) contributed to the design of the study and interpretation of data. ME and EY performed the data analysis and drafted the manuscript. All authors read, critically revised, and approved the final manuscript. EY is the guarantor of the paper.

\section{Ethics approval and consent to participate}

This study was conducted after obtaining ethical clearance from the ethical review committee of Department of Nursing and Midwifery in Addis Ababa University (ethical approval protocol number: 21/12/NURS). Besides, permission to access each public health institutions was granted by Addis Ababa City Administration Health Bureau. No personal identifier of the study participants was taken, and hence the data obtained remained anonymous. Participation in the study was only on voluntary basis. As the study entails a very minimal risk and also to ensure the anonymity of responses, respondents took part in the study after verbal informed consent.

\section{Consent for publication}

Not applicable.

\section{Competing interests}

The authors declare that they have no competing interests.

\section{Publisher's Note}

Springer Nature remains neutral with regard to jurisdictional claims in published maps and institutional affiliations.

\section{Author details}

${ }^{1}$ Department of Nursing, College of Health Sciences, Institute of Medicine and Health Sciences, Debre Berhan University, Debre Berhan, Ethiopia. ${ }^{2}$ Midwifery Advisor, UNFPA Ethiopia Country Office, Addis Ababa, Ethiopia. ${ }^{3}$ School of Allied Health Sciences, College of Health Sciences, Addis Ababa University, Addis Ababa, Ethiopia. ${ }^{4}$ Robinson Research Institute, School of Medicine, The University of Adelaide, Adelaide, Australia.

Received: 12 March 2017 Accepted: 8 January 2018

Published online: 23 January 2018

\section{References}

1. Lawn JE, Cousens S, Zupan J. 4 million neonatal deaths: when? Where? Why? Lancet. 2005;365(9462):891-900.

2. Victora CG, Bahl R, Barros AJD, França GVA, Horton S, Krasevec J, et al. Breastfeeding in the 21st century: epidemiology, mechanisms, and lifelong effect. Lancet. 2016;387(10017):475-90.

3. Edmond KM, Zandoh C, Quigley MA, Amenga-Etego S, Owusu-Agyei S, Kirkwood BR. Delayed breastfeeding initiation increases risk of neonatal mortality. Pediatrics. 2006;117(3):e380-6.

4. Sharma IK, Byrne A. Early initiation of breastfeeding: a systematic literature review of factors and barriers in South Asia. Int Breastfeed J. 2016;11:17.

5. Khan J, Vesel $L$, Bahl R, Martines JC. Timing of breastfeeding initiation and exclusivity of breastfeeding during the first month of life: effects on neonatal mortality and morbidity-a systematic review and meta-analysis. Matern Child Health J. 2015;19(3):468-79.

6. WHO. Guideline: protecting, promoting and supporting breastfeeding in facilities providing maternity and newborn services. Geneva: World Health Organization; 2017.

7. Lakew $Y$, Tabar L, Haile D. Socio-medical determinants of timely breastfeeding initiation in Ethiopia: evidence from the 2011 nationwide demographic and health survey. Int Breastfeed J. 2015;10:24.

8. Takahashi K, Ganchimeg T, Ota E, Vogel JP, Souza JP, Laopaiboon M, et al. Prevalence of early initiation of breastfeeding and determinants of delayed initiation of breastfeeding: secondary analysis of the WHO global survey. Sci Rep. 2017;7:44868.

9. Liben ML, Yesuf EM. Determinants of early initiation of breastfeeding in Amibara district, northeastern Ethiopia: a community based cross-sectional study. Int Breastfeed J. 2016;11:7.

10. Setegn T, Gerbaba M, Belachew T. Determinants of timely initiation of breastfeeding among mothers in Goba Woreda, south East Ethiopia: a cross sectional study. BMC Public Health. 2011;11:217.

11. Khanal V, Scott JA, Lee AH, Karkee R, Binns CW. Factors associated with early initiation of breastfeeding in western Nepal. Int J Environ Res Public Health. 2015;12(8):9562-74.

12. Berde AS, Yalcin SS. Determinants of early initiation of breastfeeding in Nigeria: a population-based study using the 2013 demograhic and health survey data. BMC Pregnancy and Childbirth. 2016;16:32.

13. Sharma A, Thakur PS, Tiwari R, Kasar PK, Sharma R, Kabirpanthi V. Factors associated with early initiation of breastfeeding among mothers of tribal area of Madhya Pradesh, India: a community based cross sectional study. International Journal of Community Medicine and Public Health. 2017;3(1): 194-9.

14. Alebel A, Dejenu G, Mullu G, Abebe N, Gualu T, Eshetie S. Timely initiation of breastfeeding and its association with birth place in Ethiopia: a systematic review and meta-analysis. Int Breastfeed J. 2017;12:44.

15. Hazir T, Akram D-S, Nisar YB, Kazmi N, Agho KE, Abbasi S, Khan AM, Dibley MJ. Determinants of suboptimal breast-feeding practices in Pakistan. Public Health Nutr. 2013;16(4):659-72.

16. Ayiasi MR, Van Royen K, Verstraeten R, Atuyambe L, Criel B, Garimoi CO, Kolsteren P. Exploring the focus of prenatal information offered to pregnant mothers regarding newborn care in rural Uganda. BMC Pregnancy and Childbirth. 2013;13:176.

17. Haider R, Rasheed S, Sanghvi TG, Hassan N, Pachon H, Islam S, et al. Breastfeeding in infancy: identifying the program-relevant issues in Bangladesh. Int Breastfeed J. 2010;5:21. 
18. Legesse M, Demena M, Mesfin F, Haile D. Prelacteal feeding practices and associated factors among mothers of children aged less than 24 months in Raya kobo district, north eastern Ethiopia: a cross-sectional study. Int Breastfeed J. 2014;9:189.

19. Central Statistical Agency/Ethiopia, ICF International: Ethiopia Demographic and Health Survey 2011. Addis Ababa, Ethiopia: Central Statistical Agency/ Ethiopia and ICF International; 2012.

20. Federal Ministry of Health: Ethiopian National Strategy on infant and young child feeding. Addis Ababa, Ethiopia: Family Health Department; 2004.

21. Kok MC, Kea AZ, Datiko DG, Broerse JEW, Dieleman M, Taegtmeyer M, et al. A qualitative assessment of health extension workers' relationships with the community and health sector in Ethiopia: opportunities for enhancing maternal health performance. Hum Resour Health. 2015;13:80.

22. Mengesha HG, Wuneh AD, Weldearegawi B, Selvakumar DL. Low birth weight and macrosomia in Tigray, northern Ethiopia: who are the mothers at risk? BMC Pediatr. 2017;17:144.

23. Tamiru D, Tamrat M. Constraints to the optimal breastfeeding practices of breastfeeding mothers in the rural communities of Arba Minch Zuria Woreda, Ethiopia: a community-based, cross-sectional study. South African Journal of Clinical Nutrition. 2015;28(3):134-9.

24. El-Gilany AH, Sarraf B, Al-Wehady A. Factors associated with timely initiation of breastfeeding in al-Hassa province, Saudi Arabia. East Mediterr Health J. 2012;18(3):250-4.

\section{Submit your next manuscript to BioMed Central and we will help you at every step:}

- We accept pre-submission inquiries

- Our selector tool helps you to find the most relevant journal

- We provide round the clock customer support

- Convenient online submission

- Thorough peer review

- Inclusion in PubMed and all major indexing services

- Maximum visibility for your research

Submit your manuscript at www.biomedcentral.com/submit 